\title{
Synthesis of $\mathrm{Ni}_{0.4} \mathrm{Zn}_{0.6} \mathrm{Fe}_{2} \mathrm{O}_{4}$ spinel ferrite and microwave adsorption of related polymer composite
}

\author{
K. D. Martinson ${ }^{1}$, D. D. Sakhno ${ }^{2}$, V. E. Belyak ${ }^{2}$, I. B. Panteleev ${ }^{2}$, I. V. Kochurov ${ }^{3}$, Yu. E. Zevatskiy ${ }^{3,4}$, V. I. Popkov ${ }^{1}$ \\ ${ }^{1}$ Ioffe Institute, Saint Petersburg, 194021, Russia \\ ${ }^{2}$ Saint Petersburg State Institute of Technology, Saint Petersburg, 190013, Russia \\ ${ }^{3}$ AO "NovBytChim", Saint Petersburg, 199026, Russia \\ ${ }^{4}$ Saint Petersburg Electrotechnical University “LETI”, Saint Petersburg, 197376, Russia \\ martinsonkirill@mail.ru
}

PACS 61.46.+w, 75.50.Bb, 75.60.-d

DOI 10.17586/2220-8054-2020-11-5-595-600

\begin{abstract}
Nickel-zinc ferrites are important industrial materials in the production of various types of microwave devices; therefore, studies of new methods of obtaining functional ceramic on their basis are of great interest at present. In this work, soft magnetic ceramics based on $\mathrm{Ni}_{0.4} \mathrm{Zn}_{0.6} \mathrm{Fe}_{2} \mathrm{O}_{4}$ spinel ferrite with low values of the coercive force were successfully obtained under various sintering modes (1000 and $1100{ }^{\circ} \mathrm{C}$, holding time -16 hours) based on nanostructured pre-ceramic ferrite powder synthesized by the solution combustion method. The initial powder and sintered ceramics were investigated by EDX, SEM and PXRD methods. The electromagnetic parameters of the final product were investigated by vibration magnetometry and using the method of rectangular waveguide transmissions in the X-band. It was shown that, depending on the selected sintering mode, it is possible to obtain magnetic ceramics with an average grain size in the range from 1 to $3 \mu \mathrm{m}$ and with values of the coercive force ( $\left.H_{c}\right)$ from 16.32 to $19.41 \mathrm{Oe}$, remanent magnetization $\left(M_{r}\right)$ from 3.39 to $4.31 \mathrm{emu} / \mathrm{g}$ and saturation magnetization $\left(M_{s}\right)$ from 67.90 to 78.42 emu/g. After the preparation of a ferrite-polymer composite with different content of $\mathrm{Ni}_{0.4} \mathrm{Zn}_{0.6} \mathrm{Fe}_{2} \mathrm{O}_{4}(0-50$ wt\%), it was found that the highest absorption characteristics of electromagnetic waves were observed for the sample with $40 \mathrm{wt} \%$ of spinel ferrite obtained at $1100{ }^{\circ} \mathrm{C}, 16$ hours sintering mode.
\end{abstract}

Keywords: solution combustion synthesis, spinel, ferrites, soft magnets, microwave adsorption.

Received: 7 October 2020

\section{Introduction}

Ferrites-spinels and orthoferrites of rare earth elements remain relevant objects of research for many decades due to their wide application in many areas of modern science and technology [1-3]. In addition to the well-known classical areas of their application, such as the production of hard and soft magnets [4], magnetic fluids [5], sensors [6], microwave devices [7], etc., in recent years, new opportunities have been opening up with the use of nanostructured ferrites as materials with high antibacterial activity [8], MRI contrast agents [9], photocatalysts [10], materials for wastewater treatment [11], magnetically recoverable catalysts [12] and many others. Interest in nanocrystalline ferrites is primarily due to their high chemical and thermal stability and improved electromagnetic parameters in comparison with classical micron systems of a similar composition [13-16]. Besides, obtaining multicomponent ferrites is much easier if they are in a nanostructured form [17].

One of the most interesting representatives of spinel ferrites from an industrial point of view is the multicomponent $\mathrm{Ni}-\mathrm{Zn}$ ferrite of the composition $\mathrm{Ni}_{x} \mathrm{Zn}_{1-x} \mathrm{Fe}_{2} \mathrm{O}_{4}$, which is widely used in the production of various microwave devices and as radio-absorbing materials (RAW) absorbing electromagnetic waves during which the incident energy is converted into thermal due to the interaction of waves and matter [18]. Radio-absorbing materials are the most important dual-use products widely used in both the military and civilian sectors [19]. For example, for electromagnetic shielding of aircraft and submarines, to eliminate interference and absorb secondary radiation from various electronic devices, microwave ovens, aircraft devices, etc. [20]. There are a large number of materials that, by their conductive and magnetic characteristics, can act as absorbers of electromagnetic waves. For example, polymers are not subject to corrosion and are much lighter than oxide systems, but they have much higher insulation and low stability of electromagnetic parameters [21]. This problem can be solved by adding magnetic particles to conducting polymers [22]. One of the possible variants of such magnetic particles is nickel-zinc ferrite with the composition $\mathrm{Ni}_{0.4} \mathrm{Zn}_{0.6} \mathrm{Fe}_{2} \mathrm{O}_{4}$, which has shown its effectiveness as a radio-absorbing material [23].

However, the use of ferrites as a radio-absorbing material places high demands on the stability of the magnetic and electromagnetic characteristics of the final product, which is difficult to achieve when using classical methods of production [24]. One of the promising methods for obtaining nanostructured complex oxide systems is the solution combustion method, which has shown its efficiency in the production of spinel ferrites and orthoferrites of various compositions [25-28]. Its main advantages are the ability to finely control the particle size, structure, morphology, 
magnetic and electromagnetic characteristics by varying the composition of the initial reaction medium, which was shown in detail in our previous works [29-31].

In this work, the solution combustion method was used to obtain an initial nanostructured pre-ceramic powder $\mathrm{Ni}_{0.4} \mathrm{Zn}_{0.6} \mathrm{Fe}_{2} \mathrm{O}_{4}$ with a high degree of crystallinity. The resulting powder was sintered according to classical ceramic technology, ground and dispersed into a varnish based on an acrylic copolymer in various weight percentages $(0,10, \ldots, 50 \mathrm{wt} \%)$. The resulting product was tested using a rectangular waveguide transmission line method in the X-band $(8.5-13 \mathrm{GHz})$.

\section{Experimental}

The initial nanostructured nickel-zinc ferrite of composition $\mathrm{Ni}_{0.4} \mathrm{Zn}_{0.6} \mathrm{Fe}_{2} \mathrm{O}_{4}$ was obtained by the solution combustion method using glycine as a fuel and a chelating agent. Nickel nitrate $\left(\mathrm{Ni}\left(\mathrm{NO}_{3}\right)_{2} \cdot 6 \mathrm{H}_{2} \mathrm{O}\right.$, pur., $\left.99.9 \%\right)$, zinc nitrate $\left(\mathrm{Zn}\left(\mathrm{NO}_{3}\right)_{2} \cdot 6 \mathrm{H}_{2} \mathrm{O}\right.$, pur., $\left.99.9 \%\right)$, iron nitrate $\left(\mathrm{Fe}\left(\mathrm{NO}_{3}\right)_{3} \cdot 9 \mathrm{H}_{2} \mathrm{O}\right.$, pur., $\left.98.0 \%\right)$ and glycine $\left(\mathrm{C}_{5} \mathrm{H}_{5} \mathrm{NO}_{2}\right.$, pur., $98.0 \%)$ were used. Glycine was taken in a stoichiometric ratio according to the reaction of formation of nickel-zinc ferrite:

$$
\begin{gathered}
0.4 \mathrm{Ni}\left(\mathrm{NO}_{3}\right)_{2}+0.6 \mathrm{Zn}\left(\mathrm{NO}_{3}\right)_{2}+2 \mathrm{Fe}\left(\mathrm{NO}_{3}\right)_{3}+40 / 9 \mathrm{C}_{2} \mathrm{H}_{5} \mathrm{NO}_{2} \rightarrow \\
\mathrm{Ni}_{0.4} \mathrm{Zn}_{0.6} \mathrm{Fe}_{2} \mathrm{O}_{4}+80 / 9 \mathrm{CO}_{2} \uparrow+56 / 9 \mathrm{~N}_{2} \uparrow+316 / 9 \mathrm{H}_{2} \mathrm{O} \uparrow
\end{gathered}
$$

The initial reagents were taken in a stoichiometric amount and dissolved in $50 \mathrm{ml}$ of distilled water with constant stirring for $30 \mathrm{~min}$ and a temperature of $50{ }^{\circ} \mathrm{C}$. Then, the initial solution was heated to the autoignition temperature, during which a brown-colored ferrite powder was formed. The combustion product thus obtained was thermally treated in the air at a temperature of $600{ }^{\circ} \mathrm{C}$ for 3 hours to remove unreacted organic matter and mechanically processed in a vibrating mill (balls diameter $=2 \mathrm{~cm}$ ) for 4 hours. Then the milled powder was pressed using polyethylene glycol as a binder and sintered at two temperature conditions -1000 and $1100{ }^{\circ} \mathrm{C}$ for 16 hours. The resulting ceramics were analyzed and re-ground in a planetary mill (ball diameter $=1 \mathrm{~cm}$ ) for 12 hours to obtain a submicron powder. The final composite was obtained by mixing nickel-zinc ferrite powders with a varnish based on an acrylic copolymer in various weight percentages $(0,10, \ldots, 50 \%)$ and passed electromagnetic characterization.

The morphology and chemical composition of the resulting powder and ceramics were studied by scanning electron microscopy (SEM) and energy dispersive analysis (EDX) using a Tescan Vega 3 scanning electron microscope and an Oxford Instruments X-act EDX microprobe analyzer. powder X-ray diffractometry on a Rigaku SmartLab 3 diffractometer $(\mathrm{CuK} \alpha=0.15406 \mathrm{~nm})$. Magnetic hysteresis loops were obtained using a LakeShore 7410 vibratory magnetometer. EMI absorption analysis was performed using a linear X-band method using a standard rectangular waveguide and a VectorStar MS4640B vector network analyzer.

\section{Results and discussion}

The phase composition of the obtained samples of nickel-zinc ferrite was studied by powder X-ray diffractometry (PXRD), the results of which are shown in Fig. 1. The data obtained indicate that the initial pre-ceramic powder and the ceramics obtained on its basis are single-phase samples of $\mathrm{Ni}_{0.4} \mathrm{Zn}_{0.6} \mathrm{Fe}_{2} \mathrm{O}_{4}$ (JCPDS \# 08-0234) without impurities. The most intense reflections are observed in the sample sintered at a temperature of $1100{ }^{\circ} \mathrm{C}$ for 16 hours, while the intensity of the peaks of the sample obtained at $1000{ }^{\circ} \mathrm{C}$ is slightly lower. The crystallite size of the initial powder was found using the Scherrer formula and was $47 \pm 5 \mathrm{~nm}$. Besides, using the internal standard (Si) according to the Rietveld method, the degree of crystallinity of the initial sample was estimated to be $94 \%$.

Figure 2 shows the SEM micrographs of the initial nanostructured powder and sintered ceramic. According to the data obtained, the morphology of the initial sample of nickel-zinc ferrite is a typical picture of the products of glycine-nitrate combustion at a stoichiometric ratio of glycine to nitrate-groups. Such porous agglomerates with a large number of micron and submicron pores formed during abundant gas evolution during the combustion process are often observed during the formation of other complex oxide systems $[12,17]$. It should be noted that such a morphology complicates the process of pressing and sintering the powder, which is solved by grinding the starting material in a vibrating mill, as a result of which the formed agglomerates are broken into smaller components. The data obtained show that the microstructure of the obtained ceramics significantly depends on the selected sintering temperature regimes. In the case of a sample sintered at a temperature of $1000^{\circ} \mathrm{C}$, a large number of voids between grains are observed, the size of which is in the submicron range (the average size is in the range from 0.8 to 1.3 microns). Despite the small grain size, the presence of voids significantly worsens both the magnetic and electromagnetic parameters of ceramics, which means that this temperature regime cannot be considered as optimal for sintering pre-ceramic powders obtained under conditions of solution combustion. Nevertheless, the sample sintered at a temperature of $1100{ }^{\circ} \mathrm{C}$ demonstrates a completely different microstructure from the first sample. Despite a significant increase in the grain 


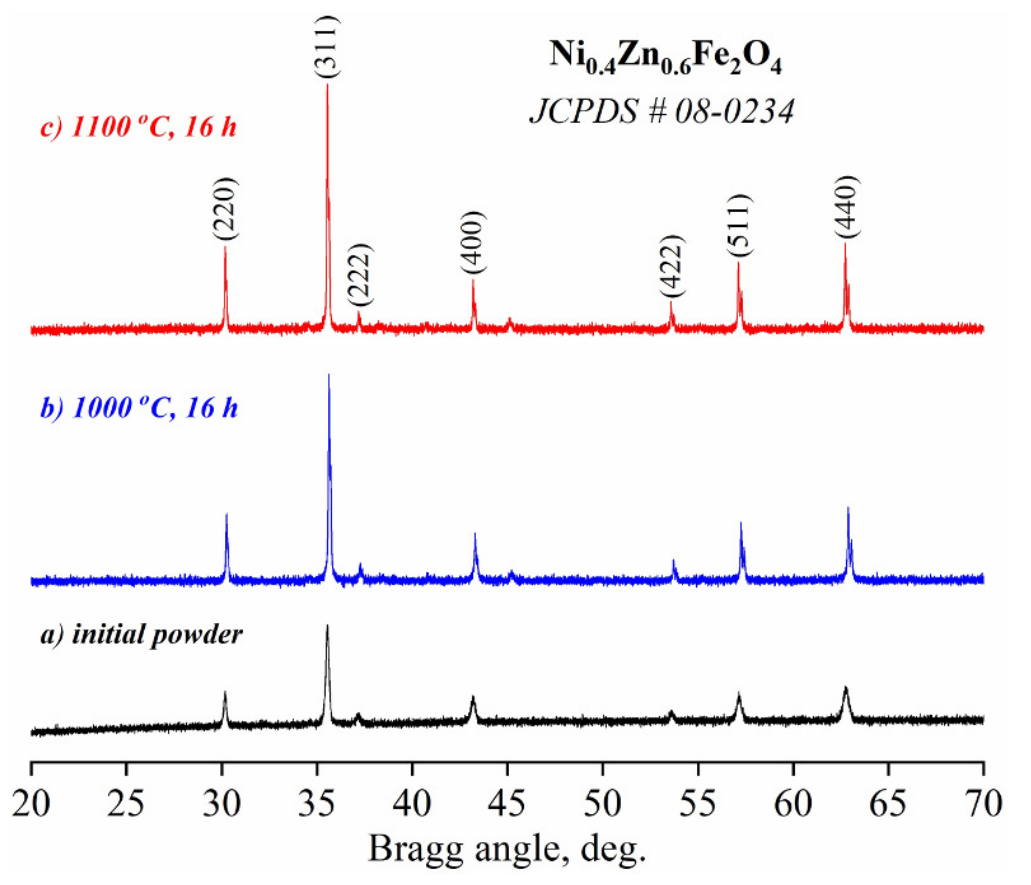

FIG. 1. PXRD patterns of the initial powder and sintered ceramics of nickel-zinc ferrite

size, which lies in the range from 1 to $3.5 \mu \mathrm{m}$, there is also a significant decrease in the number of voids between the grains, which in turn affects the quality and stability of the magnetic and electromagnetic characteristics.
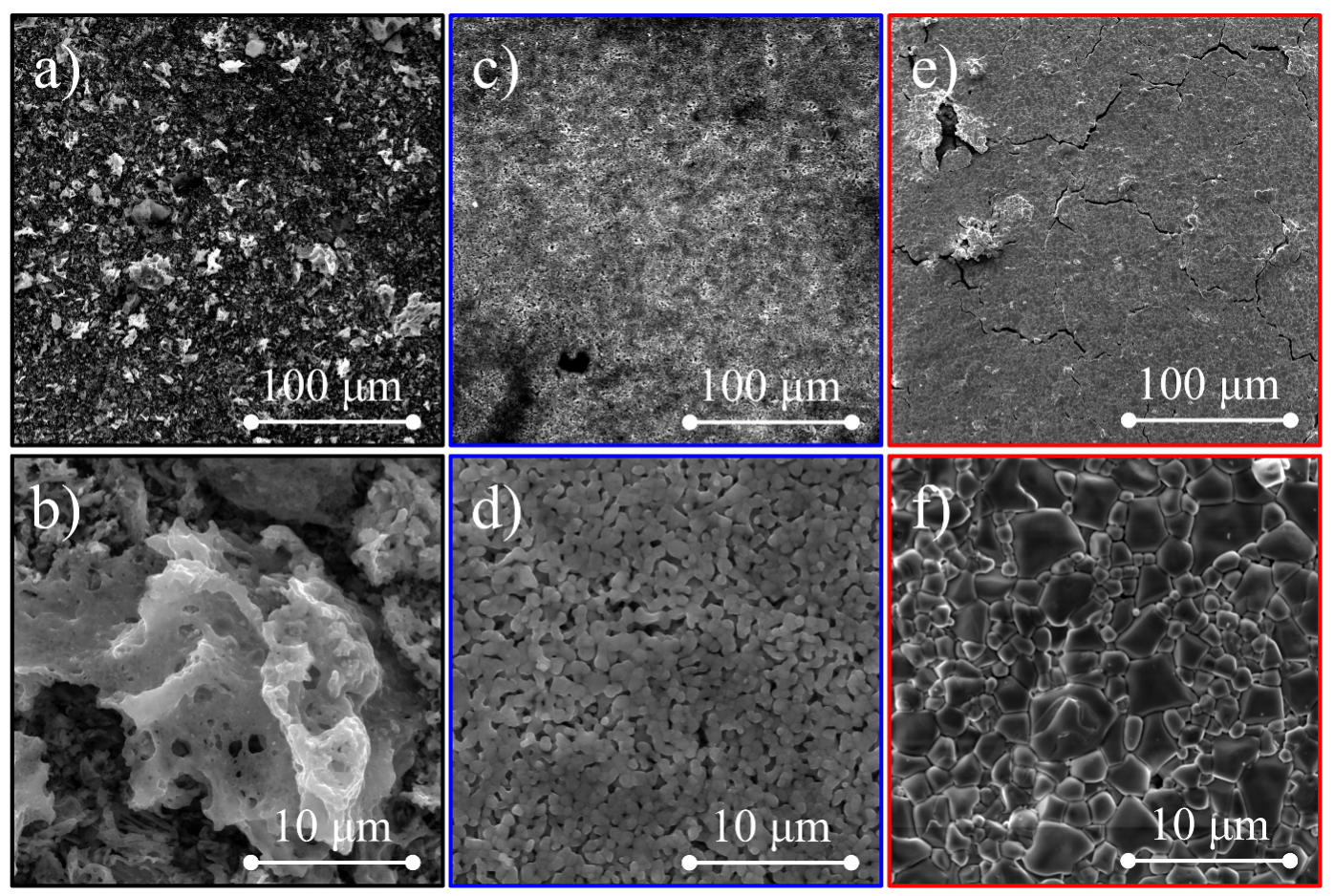

FIG. 2. SEM images of initial nickel-zinc ferrite powder obtained via glycine-nitrate combustion method (a,b) and ceramics based on them sintered at $1000^{\circ} \mathrm{C}(\mathrm{c}, \mathrm{d})$ and $1100{ }^{\circ} \mathrm{C}(\mathrm{e}, \mathrm{f})$

The hysteresis loops of samples of the initial powder and sintered $\mathrm{Ni}_{0.4} \mathrm{Zn}_{0.6} \mathrm{Fe}_{2} \mathrm{O}_{4}$ ceramics are shown in Fig. 3 . It follows from the data obtained that the highest values of the magnetic parameters $\left(H_{c}=16.32\right.$ Oe, $M_{s}=$ $78.42 \mathrm{emu} / \mathrm{g}, M_{r}=3.39 \mathrm{emu} / \mathrm{g}$ ) are observed in the sample sintered at a temperature of $1100^{\circ}$, which is due to 


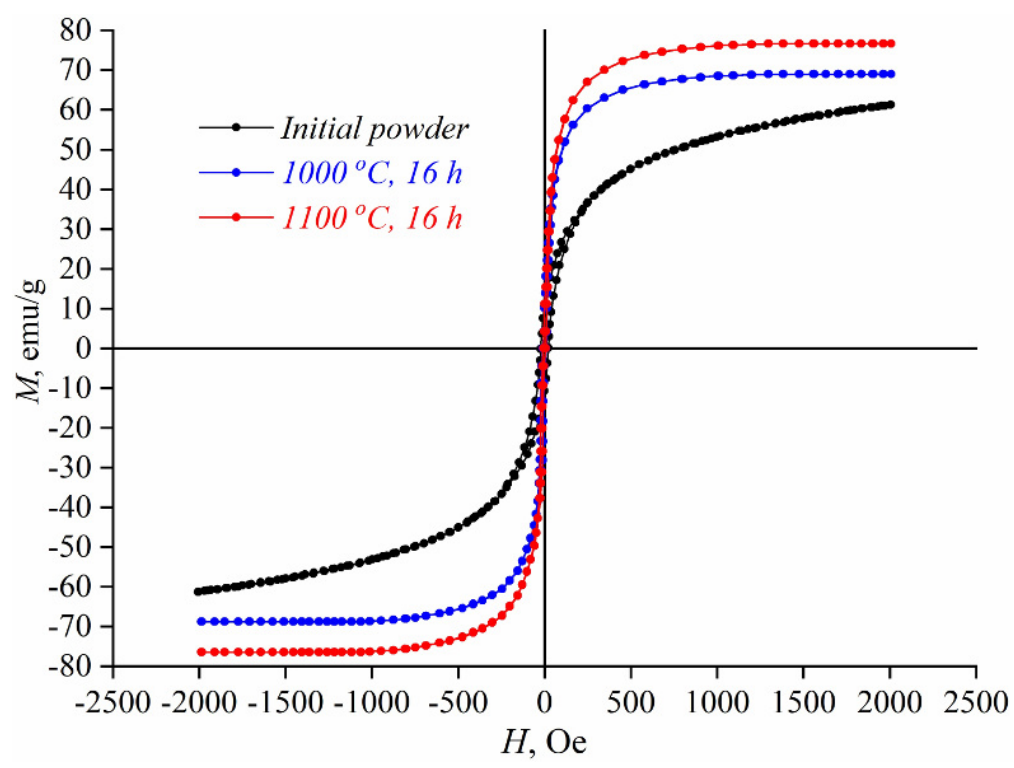

FIG. 3. Hysteresis loops of $\mathrm{Ni}_{0.4} \mathrm{Zn}_{0.6} \mathrm{Fe}_{2} \mathrm{O}_{4}$ initial powder and sintered ceramics

the peculiarity of its microstructure. It should be noted that the appearance of the loops is similar for both sintered specimens and differs in the values of saturation magnetization, remanent magnetization and coercive force (Fig. 4).

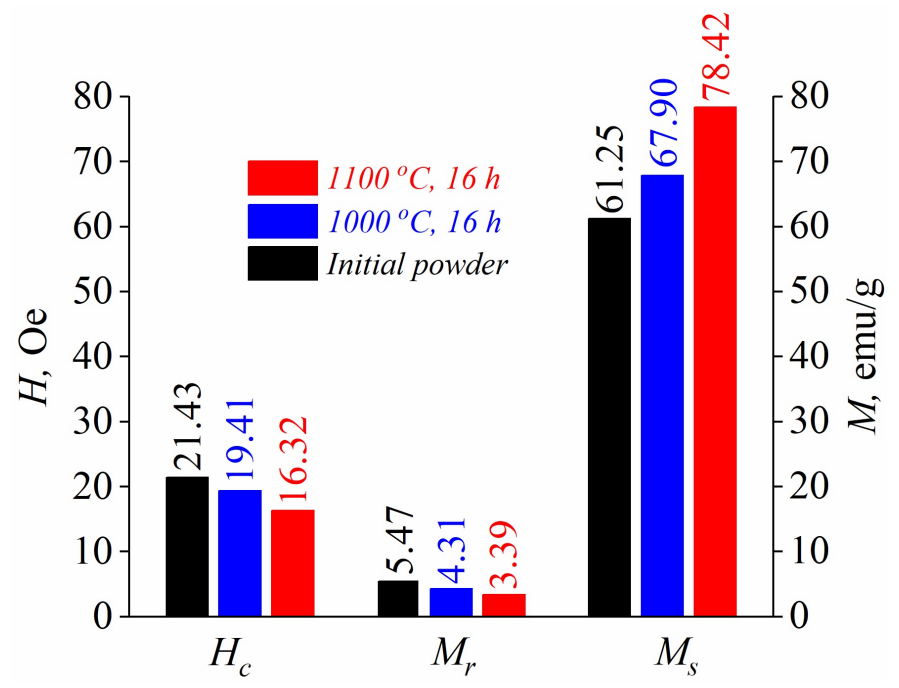

FIG. 4. Magnetic characteristics of obtained nickel-zinc ferrite samples

Figure 5 shows the curves of electromagnetic absorption for two sintered samples of nickel-zinc ferrite. The measurement was carried out on a composite obtained by dispersing the crushed ceramic in an acrylic copolymer varnish. The black curves in both figures are air measurements and were used as a reference. It is shown that with an increase in the proportion of ferrite in the polymer matrix, a significant increase in the values of electromagnetic absorption is observed. Both samples demonstrate approximately the same absorption values, with the only exception that the sample sintered at a temperature of $1100^{\circ} \mathrm{C}$ demonstrates slightly better electromagnetic characteristics. This is due to the larger grain size and fewer voids, which in turn made the grinding process more difficult. Further increase in the mass fraction of nickel-zinc ferrite was not possible due to the limits of dispersion into the initial copolymer matrix. 

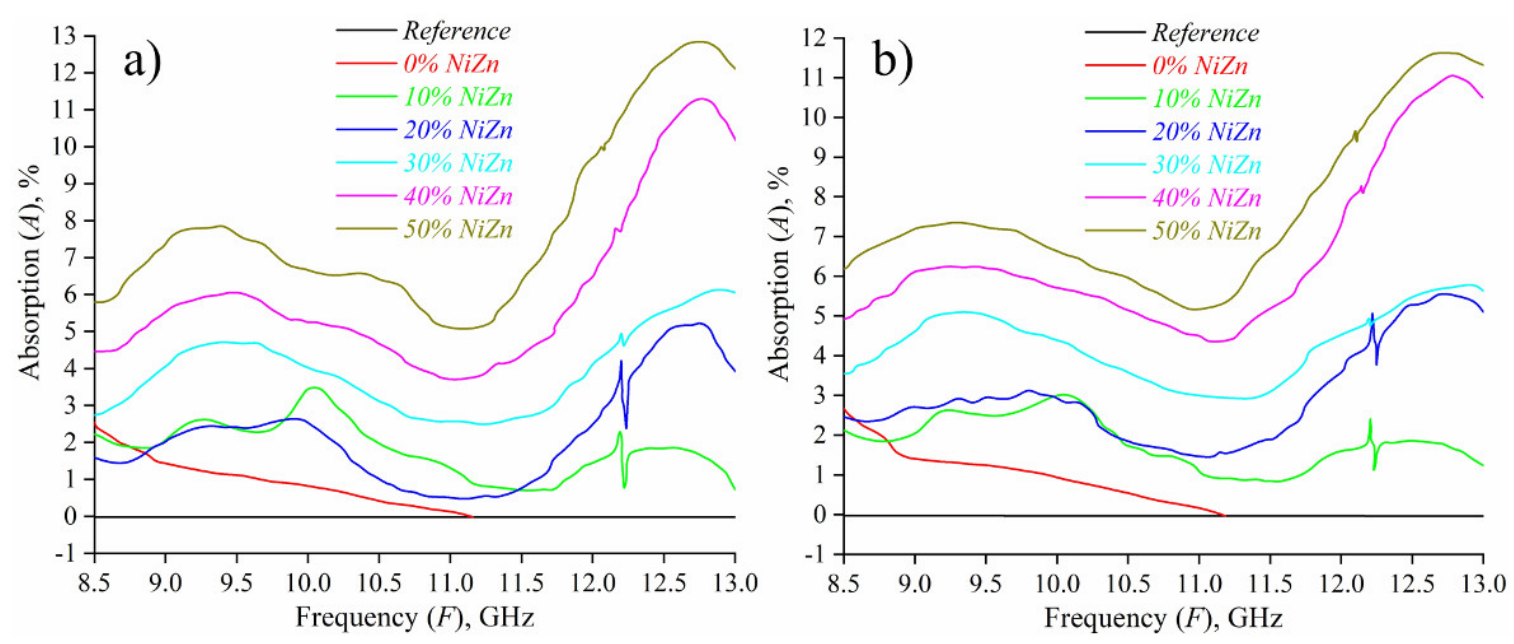

FIG. 5. Microwave absorption of $\mathrm{Ni}_{0.4} \mathrm{Zn}_{0.6} \mathrm{Fe}_{2} \mathrm{O}_{4}$-based polymer composites: nickel-zinc ferrite sintered at $1000{ }^{\circ} \mathrm{C}(\mathrm{a})$ and $1100{ }^{\circ} \mathrm{C}(\mathrm{b})$

\section{Conclusion}

Thus, a simple method was proposed for obtaining electromagnetic absorbing materials based on a copolymer matrix and ceramics of the composition $\mathrm{Ni}_{0.4} \mathrm{Zn}_{0.6} \mathrm{Fe}_{2} \mathrm{O}_{4}$ sintered from a nanostructured pre-ceramic powder synthesized by the method of solution combustion. This approach makes it possible to disperse up to 50 weight percent of spinel ferrite into the copolymer matrix and achieve high values of electromagnetic absorption. It has been shown that the most optimal sintering mode is a temperature of $1100^{\circ} \mathrm{C}$ and a holding time of 16 hours at which it is possible to obtain soft magnetic ceramics with values of coercive force, saturation magnetization and remanent magnetization equal to $16.32 \mathrm{Oe}, 3.39 \mathrm{emu} / \mathrm{g}$ and $78.42 \mathrm{emu} / \mathrm{g}$, respectively.

\section{Acknowledgments}

The reported study was funded by RFBR, project number 20-03-00976.

\section{References}

[1] Wang X., Cao S., Wang Y., Yuan S., Kang B., Wu A., Zhang J. Crystal growth and characterization of the rare earth orthoferrite PrFeO Journal of Crystal Growth, 2013, 362, P. 216-219.

[2] Martinson K.D., Ivanov V.A., Chebanenko M.I., Panchuk V.V., Semenov V.G., Popkov V.I. Facile combustion synthesis of TbFeO 3 nanocrystals with hexagonal and orthorhombic structure. Nanosystems: Physics, Chemistry, Mathematics, 2019, 10, P. 694-700.

[3] Valenzuela R. Novel applications of ferrites. Physics Research International, 2012, 2012, P. 2090-2220.

[4] Namai A., Yoshikiyo M., Yamada K., Sakurai S., Goto T., Yoshida T., Miyazaki M., Nakajima M., Suemoto T., Tokoro H., Ohsoshi S. Hard magnetic ferrite with a gigantic coercivity and high-frequency millimeter-wave rotation. Nature communications, 2012,3 , P. 1035.

[5] Dyachenko S.V., Vaseshenkova M.A., Martinson K.D., Cherepkova I.A., Zhernovoi A.I. Synthesis and properties of magnetic fluids produced on the basis of magnetite particles. Russian Journal of Applied Chemistry, 2016, 89, P. 690-696.

[6] Sutka A., Gross K.A. Spinel ferrite oxide semiconductor gas sensors. Sensors and Actuators B: Chemical, 2016, 222, P. 95-105.

[7] Martinson K.D., Kozyritskaya S.S., Panteleev I.B., Popkov V.I. Low coercivity microwave ceramics based on LiZnMn ferrite synthesized via glycine-nitrate combustion. Nanosystems: Physics, Chemistry, Mathematics, 2019, 10, P. 313-317.

[8] Camacho-Gonzalez M.A., Quezada-Cruz M., Ceron-Montes G.I., Ramirez-Ayala M.F., Hernandez-Cruz L.E., Garrido-Hernandez A. Synthesis and characterization of magnetic zinc-copper ferrites: antibacterial activity, photodegradation study and heavy metals removal evaluation. Materials Chemistry and Physics, 2019, 236, P. 121808.

[9] Hankiewicz J.H., Stoll J.A., Stroud J., Davidson J., Livesey K.L., Tvrdy K., Roshko A., Russek S.E., Stupic K., Bilski P., Campley R.E., Celinski Z.J. Nano-sized ferrite particles for magnetic resonance imaging thermometry. Journal of Magnetism and Magnetic Materials, 2019, 469, P. 550-557.

[10] Kondrashkova I.S., Martinson K.D., Zakharova N.V., Popkov V.I. Synthesis of nanocrystalline $\mathrm{HoFeO}_{3}$ photocatalyst via heat treatment of products of glycine-nitrate combustion. Russian Journal of General Chemistry, 2018, 88, P. 2465-2471.

[11] Kefeni K.K., Mamba B.B., Msagati T.A.M. Application of spinel ferrite nanoparticles in water and wastewater treatment: a review. Separation and Purification Technology, 2017, 188, P. 399-422.

[12] Martinson K.D., Kondrashkova I.S., Omarov S.O., Sladkovskiy D.A., Kiselev A.S., Kiseleva T.Yu., Popkov V.I. Magnetically recoverable catalyst based on porous nanocrystalline $\mathrm{HoFeO}_{3}$ for process of n-hexane conversion. Advanced Powder Technology, 2020,31 , P. $402-408$.

[13] Albuquerque A.S., Tolentino M.V.C., Ardisson J.D., Moura F.C.C., Mendonca R., Macebo W.A.A. Nanostructured ferrites: structural analysis and catalytic activity. Ceramics International, 2012, 38, P. 2225-2231.

[14] Trif L., Molnar-Voros N., Tolnai G., Sajo I., Meszaros S., Kalman E. Preparation and characterization of nanostructured ferrite materials by a nitrate-citrate self-combustion sol-gel synthesis. Materials Science Forum, 2008, 589, P. 167-172. 
[15] Nam J.-H., Park S. J., Kim W.K. Microstructure and magnetic properties of nanostructured NiZnCu ferrite powders synthesized by sol-gel process. IEEE Transactions on Magnetics, 2003, 39, P. 3139-3141.

[16] Fantauzzi M., Secci F., Angotzi M.S., Passiu C., Cannas C., Rossi A. Nanostructured spinel cobalt ferrites: Fe and Co chemical state, cation distribution and size effects by X-ray photoelectron spectroscopy. RSC Advances, 2019, 9, P. 19171.

[17] Martinson K.D., Ivanov A.A., Panteleev I.B., Popkov V.I. Pre-ceramic nanostructured LiZnMn-ferrite powders: synthesis, structure, and electromagnetic properties. Glass and Ceramics, 2020, 77, P. 215-220.

[18] Monteiro E.S., Kasal R.B., Moraes N.C., Melo J.C.A. Santos J.C.A., Figueiredo A. B.-H. S., Nanoparticles of Ni $i_{1-x} \mathrm{Zn}_{x} \mathrm{Fe}_{2} \mathrm{O}_{4}$ used as microwave absorbers in the x-band. Materials Research, 2019, 22, P. 20190188.

[19] Yusoff A.N., Abdullah M.H. Microwave electromagnetic and absorption properties of some LiZn ferrites. Journal of Magnetism and Magnetic Materials, 2004, 269, P. 271-280.

[20] Dosoudil R., Usakova M., Franek J., Slama J., Olah V. RF electromagnetic wave adsorbing properties of ferrite polymer composite materials. Journal of Magnetism and Magnetic Materials, 2006, 304, P. 755-757.

[21] Zhao T., Hou C., Zhang H., Zhu R., She S., Wang J., Li T., Liu Z., Wei B. Electromagnetic wave absorbing properties of amorphous carbon nanotubes. Scientific Reports, 2014, 4, P. 5619.

[22] Biswas S., Arief I., Panja S.S., Bose S. Absorption-dominated electromagnetic wave suppressor derived from ferrite-doped cross-linked graphene framework and conducting carbon. ACS Applied Materials and Interfaces, 2017, 9, P. 3030-3039.

[23] Priyadharsini P., Pradeep A., Rao P.S., Chandrasekaran G. Structural, spectroscopic and magnetic study of nanocrystalline Ni-Zn ferrites. Materials Chemistry and Physics, 2009, 116, P. 207-213.

[24] Oka H., Tanaka K., Osada H., Kubota K., Dawson F.P. Study of electromagnetic wave absorption characteristics and component parameters of laminated-type magnetic wood with stainless steel and ferrite powder for ise as building materials. Journal of Applied Physics, 2009, 105, P. 07E701.

[25] Martinson K.D., Cherepkova I.A., Panteleev I.B., Popkov V.I. Single-step solution combustion synthesis of magnetically soft NiFe ${ }_{2} \mathrm{O}_{4}$ nanopowders with controllable parameters. International Journal of Self-Propagating High-Temperature Synthesis, 2019, 28, P. $266-270$.

[26] Bharati V.A., Patade S.R., Bajaj S., Parlikar R., Keche A.P. Sondur V.V. Structural and magnetic properties of nickel ferrite nanoparticles prepared by solution combustion method. Journal of Physics: Conference Series, 2020, 1644, P. 012005.

[27] Ortiz-Quinonez J.-L., Pal U., Villanueva M.S. Structural, magnetic, and catalytic evaluation of spinel Co, Ni, and Co-Ni ferrite nanoparticles fabricated by low-temperature solution combustion process. ACS Omega, 2018, 3, P. 14986-15001.

[28] Minin R.V., Zhuravlev V.A., Lapshin O.V., Itin V.I. Svetlichnyi V.A. Nanocrystalline cobalt ferrite powders by spray solution combustion synthesis. International Journal of Self-Propagating High-Temperature Synthesis, 2020, 29, P. 1-9.

[29] Martinson K.D., Panteleev I.B., Shevchik A.P., Popkov V.I. Effect of Red/Ox ratio on the structure and magnetic behavior of Li $0.5 \mathrm{Fe}_{2.5} \mathrm{O}_{4}$ nanocrystals synthesized by solution combustion approach. Letters on Materials, 2019, 4, P. 475-479.

[30] Popkov V.I., Almjasheva O.V., Gusarov V.V. The Investigation of the Structure Control Possibility of Nanocrystalline Yttrium Orthoferrite in Its Synthesis from Amorphous Powders. Russian Journal of Applied Chemistry, 2014, 87(10), P. 1417-1421.

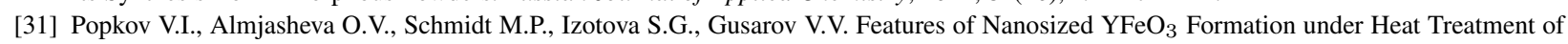
Glycine-Nitrate Combustion Products. Russian Journal of Inorganic Chemistry, 2015, 60(10), P. 1193-1198. 